\title{
ESCRITURA AUTOBIOGRÁFICA Y FICCIÓN EN ALFREDO BRYCE ECHENIQUE*
}

\author{
AUTOBIOGRAPHICAL WRITING AND FICTION \\ IN ALFREDO BRYCE ECHENIQUE'S WORKS
}

\section{SOPHIE DOROTHEE VON WERDER ${ }^{* * *}$}

\section{RESUMEN}

En la obra de Alfredo Bryce Echenique se confunden y se mezclan los géneros autobiográfico y ficcional. Ambos coinciden tanto en la temática como en el estilo. Hay mucha semejanza entre los personajes centrales de La vida exagerada de Martín Romaña y las Antimemorias, y son abundantes las coincidencias biográficas en los respectivos protagonistas. Por otro lado, en las Antimemorias se emplean técnicas narrativas de los géneros de la ficción, como la ironía, la metaforización o la creación de un estilo grotesco y lleno de exageraciones. En Bryce Echenique, realidad y ficción borran sus límites, creando una nueva dimensión literaria.

Palabras clave: Exilio, autobiografía, diario personal, memoria, desdoblamiento, fragmentación, ficcionalización, hibridación genérica.

\section{ABSTRACT}

In the works of Alfredo Bryce Echenique, autobiographical and fictional genres mix. Both agree in subject matter and style. There are many similarities between the central characters of The exaggerated life of Martín Romaña and the Antimemorias, and biographical coincidences abound in the respective protagonists. On the other hand, narrative techniques of different fictional genres are used in Antimemorias, such as iro-

* Producto derivado del proyecto Literatura e hiperrealidad: un estudio comparado, realizado con apoyo del Centro de Investigaciones de Comunicaciones de la Facultad de Comunicaciones de la Universidad de Antioquia, Estrategia de Sostenibilidad 2013-2014.

${ }^{* *}$ Grupo de Estudios Literarios (GEL), Departamento de Lingüística y Literatura, Facultad de Comunicaciones, Universidad de Antioquia UDEA, Calle 70 № 52-21, Medellín, Colombia. E-mail: svonwerder@gmail.com 
ny, metaphors or the creation of a grotesque style full of exaggerations. In Bryce Echenique, reality and fiction go beyond the boundaries, creating a new literary dimension.

Key words: Exile, autobiography, personal diary, memory, split personality, fragmentation, fictionalization, generic hybridism.

Recibido: 13.08.13. Aceptado: 20.11.14.

Definitivamente, soy al revés. Mis novelas, por ejemplo, se han tropezado siempre con los hechos reales como si éstos fueran un obstáculo para la vida misma de sus personajes" (Bryce Echenique, 2005: 348).

\section{LA VIDA EXAGERADA DE MARTÍN ROMAÑA, ¿UNA NOVELA AUTOBIOGRÁFICA?}

$\mathrm{P}$

OR LO GENERAL, los lectores tienden a creer que las novelas de Alfredo Bryce Echenique son autobiográficas. Y si esto es el caso de su obra novelística en general, más lo es cuando críticos o lectores se refieren a La vida exagerada de Martín Romaña (2005), novela publicada en 1981. Niño de Guzmán, por ejemplo, opina que "sin duda, Martín Romaña es uno de los personajes bryceanos más significativos por cuanto se trata de un verdadero alter-ego de Bryce" (Niño Guzmán y Vargas Llosa, A., 1984: 53). Al publicarse la primera parte de las Antimemorias, en 1993, Carrera Pedroza (1995: 41) observa que muchas peripecias allí narradas ya habían sido contadas en la novela.

Sin embargo, Bryce ha declarado en varias entrevistas que él conscientemente está separando su vida real de la literaria: "Se ha dicho de mí que soy un escritor profundamente autobiográfico, cosa que no me creo, porque sé cuál es la historia de mi vida" (Lafuente, 1991: 30). Puede ser esta la razón para que Bryce se negara rotundamente a interpretar a Martín Romana, en una adaptación al cine de la novela que Tomás Gutiérrez Alea pensaba realizar. Debido a la negativa de Bryce, Gutiérrez Alea finalmente desiste de la idea (Bryce Echenique, 1993: 443).

Sobre La vida exagerada de Martín Romaña, Bryce declara que "Martín Romaña es un apoderado mío; es un personaje creado para decir las cosas con distancia y humor y no decirlas autobiográficamente sino, por ese mismo vuelo que coge, darle libertad a la novela por encima de la biografía" (Niño Guzmán, y Vargas Llosa, A., 1984: 53). Bryce Echenique pone distancia entre su vida y la del protagonista, interponiendo a Martín Romaña 
como autor ficticio de la novela. Además, en esta obra deambula un personaje llamado Alfredo Bryce Echenique (Bryce Echenique, 2001: 227-229, $234,264,288,289,295,305,340,448,455-459)$, con la trayectoria literaria del autor, lo cual igualmente responde a la voluntad del autor de distanciarse y no ser identificado con su protagonista. En este sentido, el mismo autor reconoce que su aparición en la novela "da un afán testimonial a una gran mentira. En otras palabras, lo que trato de probar es que estoy haciendo literatura, que no estoy escribiendo una autobiografía ni nada por el estilo" (Lafuente, 1991: 66). Lo ficticio de la novela resulta entonces paradójicamente reforzado por la inclusión del autor real, Bryce Echenique, como personaje.

No obstante, existen casi innumerables coincidencias biográficas entre Alfredo Bryce Echenique y Martín Romaña, tanto en los aspectos fundamentales como en algunos detalles de su vida parisina, de aparente insignificancia. Después de hacer un breve resumen del argumento de la novela, repasaremos algunos temas que permiten relacionar la biografía del autor con la trayectoria del protagonista-narrador de su novela.

La novela La vida exagerada de Martín Romaña relata la vida de Martín Romaña en París, sus viajes por otros países europeos, y sus recuerdos del Perú. Martín Romaña es peruano, de clase alta, y llega a París con ambiciones de ser escritor. Poco después de su llegada, le sigue su novia Inés, peruana también, con la cual se casa. Pronto la pareja se involucra en las actividades de un grupo de latinoamericanos de izquierda revolucionaria, que subsisten con becas y el dinero que les envía la familia. Martín es expulsado del grupo marxista, hecho que cuenta con la aprobación de Inés, su esposa. En la medida que se va deteriorando la relación con su esposa, Martín va cortando poco a poco el contacto con el mundo exterior. Su aislamiento lo lleva a un colapso físico y mental. Tiene que pasar por un doloroso y humillante "vía crucis rectal". Inés lo abandona y se va a América. Finalmente, Martín logra reanudar el contacto con la realidad gracias a la psicoterapia del Doctor Llobera, la ayuda de Octavia de Cádiz y el efecto terapéutico de la escritura.

Vamos ahora a realizar una revisión de las coincidencias biográficas entre autor y el personaje principal de La vida exagerada de Martín Roma$\tilde{n} a$, quien se parece mucho al protagonista de las Antimemorias. Ambos se muestran como sensibles, tímidos, y se ven envueltos en problemas absurdos y grotescos.

Tanto Alfredo Bryce Echenique como Martín Romaña pertenecen a la oligarquía limeña, con un padre que es banquero y por el lado materno, con

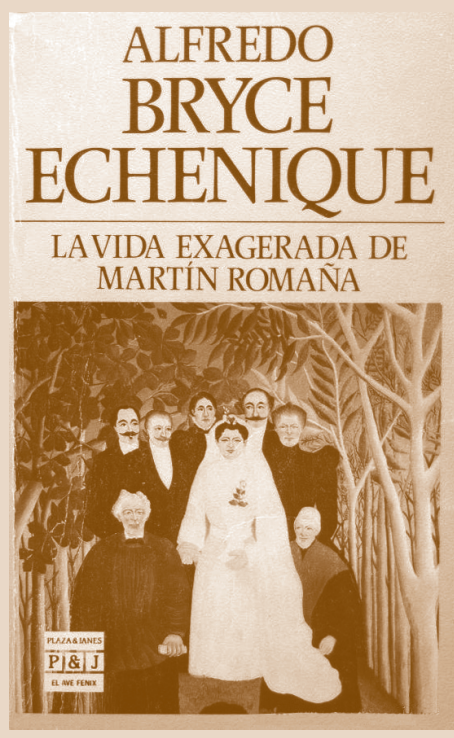

LAVIDA EXAGERADA DE 
un antepasado que fue presidente de la República ${ }^{1}$. Ambos se criaron en un ambiente europeizante, con vastas bibliotecas privadas, de autores casi exclusivamente europeos. Por cierto, a los dos, su biblioteca entera se les cae al agua al llegar a Europa (Bryce Echenique, 2005: 266; 2001: 28).

Las respectivas madres de Martín Romaña y Alfredo Bryce Echenique adoran a Proust (1993: 21; 2001:242). Ambas tienen tendencia por el alcoholismo (2005: 389; 2001: 230).

Tanto Martín Romaña como Alfredo Bryce Echenique estudian Derecho para complacer al padre, pero finalmente viajan a París a pesar de la oposición de éste. Ambos salen del Perú en el año 1964. Martín Romaña, al igual que Bryce Echenique, desea ser escritor y siente la necesidad de salir de su país para lograrlo.

Los dos siguen los pasos de Ernest Hemingway, buscando el París mitificado por éste, y sintiéndose defraudados finalmente. La novela realiza una desmitificación radical de París, y en las Antimemorias se manifiesta la misma desilusión con respecto a París como meta cultural (2005: 99; 2001: 52).

Sin embargo, en el exilio, Bryce Echenique y Martín Romaña comienzan a escribir, el exilio les 'enseña' a escribir (Bryce Echenique, 1988: 143; 2001: 309).

Abundan, por lo demás, las coincidencias que se refieren a ciertos detalles de su vida en París. Tanto Bryce Echenique como Martín Romaña alquilan un pequeño apartamento y reparten las copias de sus llaves, para que otros muchachos latinoamericanos, izquierdistas, que viven en un hotel sin baño, se puedan duchar en su casa. Martín Romana tiene problemas con madame Labru, su portera, que vigila constantemente a sus arrendatarios, y les impone todo tipo de restricciones (Bryce Echenique, 2001: 190). También Alfredo Bryce Echenique se queja en "El París que yo viví" de las porteras parisinas y de sus miradas de control (1988: 145).

Martín Romaña y Alfredo Bryce trabajan durante muchos años como profesores universitarios. Y hasta en la relación amorosa forman parte de constelaciones parecidas. La esposa de Martín Romaña es, en un comienzo, ultrabeata, para luego comprometerse de manera incondicional con el marxismo (2001: 190). También la primera esposa de Bryce, Maggie Revilla, era "tan católica que cuando la conocí de vista y me enamoré a primera vista estaba a punto de entrar en un convento" (Bryce Echenique, 1993: 336).

\footnotetext{
${ }^{1}$ La madre de Alfredo Bryce Echenique es descendiente directa de José Rufino Echenique, quien gobernó Perú entre 1851 y 1854; el bisabuelo de Martín Romaña también fue presidente de la República (Bryce Echenique, 2001: 516).
} 
Más adelante, sin embargo, al descubrir el comunismo latinoamericano en París, decide que "ya no iría nunca más a misa y que sólo había sido católica porque la habían engañado desde niña" (1993: 345). Finalmente, al igual que Inés de Romaña, Maggie Revilla se convierte en marxista ortodoxa y termina abandonando a su esposo por lo que considera sus "insoportables contradicciones burguesas" (1993: 358).

El trasfondo histórico de la novela es la revolución del 68 en París, y en una entrevista, el mismo Bryce Echenique equipara su relación con los movimientos de mayo del '68 con la de Martín Romaña: "Martín sale a la calle, a la revolución, para conquistar a una mujer, y nada más. Yo viví Mayo del 68 como una aventura erótica (...)" (Lafuente, 1991: 52). Asimismo, Martín Romaña y Alfredo Bryce Echenique descubren que los movimientos de mayo '68, para muchos compañeros son una moda pasajera. La actitud de éstos se caracteriza por sus incoherencias y contradicciones. Martín Romaña presiente que a los compañeros revolucionarios les espera un próspero y burgués futuro en América. Su visión y su experiencia corresponden con las que Bryce Echenique expresa en sus Crónicas personales: "París-ciudad en la que descubriste los partidos políticos del progreso y del cambio. Y el infantilismo y el arribismo político. París-ciudad en la que aprendiste a comprender que mucha de aquella gente atravesaba una febril primavera porque estaba en París, para luego retornar a Latinoamérica a engordar o perder el pelo en alguna burocracia militar o simplemente de derecha" (Bryce Echenique, 1988: 144). También las Antimemorias reflexionan sobre la actitud superficial y facilista de la izquierda latinoamericana en Europa: "América Latina no podía ser sino de izquierda en una Europa conservadora y paternalista. Contra esa Europa se vivía muy bien, y contra esa Europa y en esa Europa se vivía aún mejor" (Bryce Echenique, 2005: 54).

Las coincidencias anotadas permiten establecer fehacientemente que $\mathrm{La}$ vida exagerada de Martín Romaña contiene variados elementos autobiográficos, aunque por eso, no se pueda afirmar que la novela sea propiamente una autobiografía.

Ha sido a partir del siglo XIX que algunos autores comenzaron a mezclarse con la vida de sus personajes, lo cual provoca una lectura como la que acabamos de realizar, una lectura en la cual se procura detectar las huellas autobiográficas que dejó el autor en el texto. Sin embargo, la presencia o ausencia de los caracteres sustanciales y semánticos del género autobiográfico, tal como las define Puertas Moya (2004), discriminarían si estamos ante un fenómeno autobiográfico pleno o un acto autobiográfico híbrido, en el que se han utilizado elementos propios de la autobiografía con otros ajenos. 
Observamos que La vida exagerada de Martín Romaña cumple con las características de la autorreferencialidad, de un texto que gira en torno al 'yo', que construye un proyecto autobiográfico del protagonista (el de ser escritor), en el que se refleja un cierto narcisismo, se narra la intimidad del personaje principal (sus relaciones amorosas, sus deseos, angustias y depresiones), y se da testimonio de las circunstancias que le tocaron vivir (mayo del '68). Sin embargo, la autobiografía como tal se basa en la identificación entre el autor real (escritor) del texto, el narrador y el personaje protagonista del texto. En La vida exagerada de Martín Romaña, a pesar de mucha semejanza o similitud, no hay identificación, el personaje narrado tiene otro nombre propio.

Se puede afirmar entonces, que entre los múltiples materiales que Bryce emplea para construir su texto, se vale también de experiencias personales que el mismo autor ha contado en otros textos que sí tienen el carácter de autobiográficos y que permiten, entonces, el cotejo. Sin embargo, lo más significativo de esas presencias, 'trozos de vida' en la novela, es que convertidas en textos se someten a la estrategia general de la novela bryceana que consiste en suprimir, borrar o hacer ambigua la distinción entre realidad y ficción y, por tanto, volverla insignificante.

\section{LAS ANTIMEMORIAS, ¿UN GÉNERO FICCIONAL?}

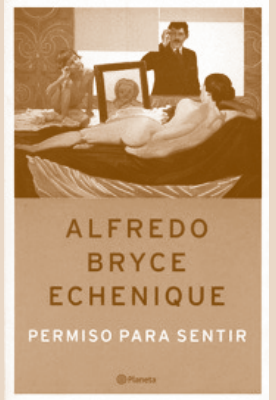

Los dos gruesos tomos de las Antimemorias, tituladas Permiso para vivir (Bryce Echenique, 1993) y Permiso para sentir (Bryce Echenique, 2005), respectivamente, son divididos cada uno en dos partes. Las respectivas primeras partes se llaman 'Por orden de azar', y hablan, entre otros temas, del exilio europeo. Estas partes consisten en una recopilación de notas autobiográficas, no ordenadas cronológicamente, que iluminan ciertos momentos en la vida del autor. La segunda parte de Permiso para vivir, 'Cuba a mi manera', trata de los viajes a Cuba. Esta parte corresponde en mayor medida con una autobiografía orgánica y lineal, y relata las relaciones del autor con la Cuba castrista, que se convirtieron en la historia de una decepción. La segunda parte de Permiso para sentir, 'Ché te dice la patria?', habla del fracasado intento de volver a vivir en el Perú en 1999. También esta parte se parece a una autobiografía convencional y lineal. Tenemos, entonces, el contraste de unas partes que nos parecen más libres, ficticias, y otras que corresponden básicamente al género de la autobiografía. Ortega observa en las Antimemorias, un desdoblamiento del sujeto, porque la persona de 
la primera parte resiste ser el personaje de la segunda y aunque en realidad lo excede, lo suyo no es dar cuento sino tramar su propio cuento (Ortega, 1993).

Revisaremos aquí, en qué sentido y hasta qué punto las Antimemorias se pueden considerar una autobiografía, y en qué medida exceden los límites de este género, presentándonos a un personaje ficticio.

En principio, como género memorístico o autobiográfico, las Antimemorias responden a la necesidad de registrar y registrarse como 'yo', a la necesidad de usar la literatura como instrumento eficaz para la introspección.

El narcisismo, según Puertas Moya uno de los caracteres semánticos del género autobiográfico, aquí no sólo lleva a exhibir las virtudes del autor, como la agudeza intelectual, la generosidad, la sensibilidad y su capacidad de entrega, sino también sus debilidades, como la inseguridad, la mente caótica, la dificultad para enfrentarse con los problemas de la vida cotidiana. Ni siquiera se esconden temas muy personales y delicados como la tendencia depresiva (Bryce Echenique, 1993: 289, 360), el nerviosismo (Bryce Echenique, 1993: 348), la tentación del suicidio (1993: 208, Bryce Echenique 2005: 304), una estadía en la clínica Rech, en el pabellón para los enfermos mentales (1993: 283), o el alcoholismo de la madre (2005: 389). El autor se ironiza y hasta se ridiculiza a sí mismo, lo cual suscita la aceptación, la simpatía y la compasión del lector. Carrera Pedroza opina que el propósito central de los libros es "dar una imagen desenfadada, jovial, vitalista y siempre honrada del protagonista, cuya misma timidez, cifrada en el patológico temblor de las manos, encaja dentro de ese propósito" (Carrera Pedroza, 1995: 42).

Hay una metarreflexión acerca de lo que Puertas Moya llama el 'proyecto autobiográfico', lo cual correspondería a otro rasgo esencial o semántico de la autobiografía. Bryce reconoce que hay unos momentos o oportunidades "que se le presentan a uno para escoger sus coincidencias y convertirlas en destino" (Bryce Echenique, 2005: 42). Un ejemplo de ello sería la manera cómo reflexionan las Antimemorias sobre la pérdida de un manuscrito, recién redactado, a la llegada a París y Barcelona, respectivamente, coincidencia que cobra "el valor de un aviso terrible" (1993: 208). También la convicción de tener que vivir en Europa para poder escribir, obviamente forma parte del 'proyecto autobiográfico' que plantean las Antimemorias.

No obstante las características propias del género autobiográfico presentes en las Antimemorias, desde la imposición del título, Bryce Echenique las ubica en una frontera genérica incierta, que corresponde con una vacilación entre el estatuto literario o testimonial. En la 'Nota del autor' 
que introduce a Permiso para sentir, Bryce explica que el título se debe a que "uno ha leído demasiado sobre memorias, autobiografías y diarios íntimos", además, señala que aquí se trata de "una sarta de capítulos totalmente desabrochados en su orden cronológico y realmente escritos 'por orden de azar"” (Bryce Echenique, 2005: 12).

Según Frank Kermode, el proceso de la escritura normalmente aleja al escritor de la angustia ejerciendo una función terapéutica: la de dar forma al desorden de la experiencia (Kermode, 1983: 42). Las Antimemorias, sin embargo, no pretenden ni procuran ordenar o esclarecer los acontecimientos. Los capítulos, como ya señalamos, no llevan fecha ni están ordenados. A veces, el enunciador se refiere a un pasado alejado en tiempo y en espacio, lo que es común en la autobiografía, a veces se posiciona frente a un pasado inmediato, lo cual corresponde al género del diario personal. A la vacilación temporal se suma en varias partes la indeterminación de la voz enunciadora. En vez de lograr realmente registrarse como 'yo', el enunciador de las Antimemorias se refleja como un ser borroso, incierto, confuso y ambiguo. Entre los epígrafes que se citan, se encuentra uno de Montaigne que advierte sobre la constante transformación del 'yo' y la imposibilidad de fijar una identidad cambiante. Dice Montaigne que "quien se mira con cuidado, no se encuentra dos veces en el mismo estado (...) Si hablo diversamente de mí, es que me miro diversamente. (...) cualquiera que se mire con atención encontrará en sí mismo e incluso en su juicio esta volubilidad y discordancia" (Bryce Echenique, 2005: 7). En las Antimemorias, las palabras parecen no lograr establecer un nexo con el 'yo', ni con la vida o el pasado; la voz enunciadora, en algunas partes, enfrenta su propia desaparición en un presente difuso.

Las Antimemorias pertenecen al campo autoficcional que amplía la narración autobiográfica de ciertos hechos vividos, e incorpora los sueños, los deseos, los sentimientos y la disposición psíquica del individuo. Se están mezclando no sólo los diferentes géneros autorreferenciales, como el diario íntimo, la autobiografía y la memoria, sino que se integran otros elementos propios de los géneros de ficción como la novela o el cuento.

Un recurso muy bryceano y casi omnipresente en las novelas y también en las Antimemorias del autor, es la ironía. En las Antimemorias, Bryce ironiza hasta sobre un asunto tan grave como un fracasado suicidio suyo, que se presenta como un ejercicio de harakiri (2005: 304). La ironía frecuentemente deriva en la exageración, en un realismo grotesco y absurdo, que deja de ser creíble y real. La ironía misma entonces, hace que los textos 
excedan o rebasen el realismo y se convierten en ficción. Otro ejemplo sería el reencuentro después de muchos años con la madre, cuando ésta cayó en estado de coma. El alejamiento y enajenamiento se traduce de la siguiente manera: El personaje de las Antimemorias llega a una sala con doce señoras en estado de coma, que se parecen por el color de su pelo y la sonda en la nariz. No reconoce a su madre, y "las besé a todas, como no" (2005: 560).

Otro recurso narrativo ampliamente empleado en la novela, que contribuye al carácter ficcional de los textos, es la metaforización. En el "Desasosiego de las cosas" (2005: 285-298), por ejemplo, el comportamiento de ciertos objetos metaforizan el estado de ánimo y el desarraigo de su dueño. Así, en algunos momentos de las Antimemorias, Bryce se plasma a sí mismo como figura literaria, envuelto en recursos propios de la ficción.

También se encuentran partes abiertamente ficticias en las Antimemorias, como una carta de un tal Luis a su hermana Carla (2005: 285-298).

Encontramos entonces en Bryce Echenique un tipo de narración diferente, que se sitúa más allá de las tradicionales distinciones entre lo ficcional y lo no ficcional o lo autobiográfico. Bryce reconoce que “(...) en mí ha habido siempre una enorme incapacidad para discernir entre realidad y ficción" (Lafuente, 1991: 89). Y cuando de sus historias y su obra se trata, niega que lo real o lo ficticio tengan relevancia alguna: "Me ha ocurrido que conversando con amigos españoles he comenzado a contar historias de mi familia y, de pronto, la historia sigue por un lado que no tiene nada que ver con mi familia, es decir, la he mezclado con otras cosas y me he encontrado con alguien que al final me lleva a un lado y me pregunta: 'Oye, ¿pero es cierto?' y me gustaría contestar: 'y a mí qué me importa' (....)” (Lafuente, 1991: 86).

La escritura bryceana, en realidad se sirve de elementos de procedencia heterogénea, con irreverencia y hasta desparpajo, jugando con ellos y resistiéndose a cualquier encasillamiento. Dado que se cuestionan y se niegan los conceptos de 'realidad' y 'ficción' y se les resta toda importancia, no se trata de un movimiento oscilante entre aquellos conceptos, sino de una mayor apertura, de una creación más libre que posibilita la conquista de un tercer espacio, un 'entre', intersticial. El autor manifiesta su intención de distanciarse del material narrativo, para darle carácter ficcional y hacer explícito su trabajo de escritor, sin embargo, los trozos del texto que reconstruyen el pasado del autor colaboran con la hibridación del plano real y ficcional. 


\section{REFERENCIAS}

Bryce Echenique, A. (1988). Crónicas personales. Barcelona: Anagrama.

(1993). Permiso para vivir (Antimemorias). Buenos Aires: Planeta S.A.I.C..

(2001). La vida exagerada de Martín Romaña. Barcelona: Anagrama. (2005). Permiso para sentir (Antimemorias 2). Buenos Aires: Planeta S.A.I.C.

Carrera Pedroza, L. (1995). Reflexiones de lozanía. Venezuela: Fondo Editorial Toromaina.

Kermode, F. (1983). El sentido de un final. Barcelona: Gedisa.

Lafuente, F. R. (1991). Alfredo Bryce Echenique: La Semana de Autor sobre Alfredo Bryce Echenique tuvo lugar en Madrid del 23 al 26 de noviembre de 1987, en el Instituto de Cooperación Iberoamericana. Madrid: Instituto de Cooperación Iberoamericana, Ediciones de Cultura Hispánica.

Niño Guzmán, G. y Vargas Llosa, Á. (1984). "Una larga tarde con Bryce”. Oiga (Lima), 16 de julio, 53-56.

Ortega, J. (1993). “Las antimemorias de Bryce”. Bajo Palabra (Suplemento cultural de El Diario), Caracas: No 52, año II.

Puertas Moya, F. E. (2004). Aproximación semiótica a los rasgos generales de la escritura autobiográfica. España: Universidad de La Rioja. 